\title{
Accidental exposure to isocyanate fumes in a group of firemen
}

\author{
A. T. AXFORD†, C. B. MCKERROW*, A. PARRY JONES, and \\ PAMELA M. LE QUESNE \\ MRC Pneumoconiosis Unit, Penarth, Glamorgan and MRC Toxicology Unit, \\ Carshalton, Surrey
}

\begin{abstract}
Axford, A T., McKerrow, C. B., Parry Jones, A., and Le Quesne, P. M. (1976). British Journal of Industrial Medicine, 33, 65-71. Accidental exposure to isocyanate fumes in a group of firemen. A total of 35 firemen involved in fighting a fire in a factory in which polyurethane foam was made were exposed to fumes of toluene di-isocyanate from two large storage tanks which were damaged during the fire, resulting in massive spillage. Most of the men experienced symptoms during the fire or during the three weeks after it. The symptoms were mainly gastrointestinal, respiratory, or neurological. Altogether 15 men described gastrointestinal symptoms which subsided within two days of onset. Respiratory symptoms were described by 31 men and were most pronounced during the three days after the fire, thereafter tending to improve. The neurological findings are described separately. When the men were reviewed at six months there was a suggestion that some of them might have sustained long-term damage to the respiratory tract, and almost four years later 20 men had persistent respiratory symptoms. Serial measurements of ventilatory capacity revealed a marked decline in the first six months although this was not sustained.
\end{abstract}

A fire occurred in November 1967 at a factory manufacturing polyurethane foam, during which 35 firemen were exposed to chemical fumes including toluene di-isocyanate (TDI). The men were part-time firemen with the exception of five full-time officers. The fire started in a part of the factory where finished blocks of foam were stored and, because of the highly inflammable nature of the foam, the fire spread rapidly to the production section where several tanks of TDI and other chemicals used in the manufacturing process were stored (Table 1).

The flexible polyurethane foam was manufactured by reacting toluene di-isocyanate and a propylene glycol, together with various additives. In the factory were several tanks each containing 13500 litres TDI. When the fire had been in progress for

*Dr McKerrow died in July 1972

†Now Bronglais Hospital, Aberystwyth
TABLE 1

\section{CHEMICALS OTHER THAN TDI STORED IN THE FACTORY}

Tri-(2,2-dichloropropyl) phosphate

Tri-(2,2-dibromopropyl) phosphate

Stannous octanoate

Trichlorofluoromethane

Dimethylpolysiloxane

Tri-(2-chloroethyl) phosphate

1 methyl cyclohexyl derivative of selected xylerols

2 dimethylamino ethanol

1,3-diaminopropane

about an hour the smoke assumed a distinctive metallic taste and smell. At this stage all the personnel in the production section of the building put on breathing apparatus. A plastic-coated leather diaphragm valve on one of the tanks of TDI was 
found to be leaking but attempts to close the valve were unsuccessful. Shortly afterwards a second valve on the same tank was found to be leaking and again could not be closed. It was felt likely that the valves had been damaged by the heat of the fire, and in order to reduce the temperature of the leaking tank four men sprayed their hoses on to it until the fire was under control. It was estimated that approximately 4500 litres TDI escaped from the tanks.

After the fire several of the men were involved in removing fire fighting apparatus from the building. Some of this was heavily contaminated with TDI and hoses had to be removed from a deep layer of the liquid. The men involved in this exercise and those who attempted to turn off the leaking valves later described how their uniforms had become soaked with TDI which subsequently dried to leave a white powdery coating of polyurethane.

There is, therefore, evidence that several firemen were heavily exposed to fumes of, or were in contact with, liquid TDI.

\section{Clinical findings}

Altogether 35 men of mean age 40.5 years (Fig. 1) were interviewed one week after the fire and again two weeks later. On the second occasion chest radiographs were obtained on all the men and tests of ventilatory capacity were performed on 32 of them (mean age 41.1 years). One, a paint sprayer, had previously been exposed to isocyanate fumes and two others had been employed at the factory in which the fire occurred, but they had not worked in the section where TDI was used. A total of $\mathbf{3 1}$ men were subsequently seen on two further occasions at six months and $\mathbf{4 4}$ months after the fire when a further clinical examination was made and measurements of ventilatory capacity were obtained.

Two of the 35 men had no symptoms at the time of the fire nor at any time thereafter. The remainder

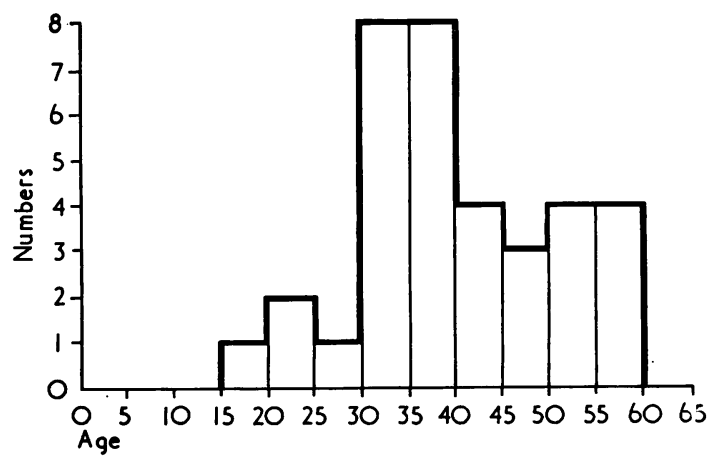

FIG. 1. Age distribution of 35 firemen exposed to isocyanate fumes. complained of gastrointestinal, respiratory, and/or neurological symptoms either at the time of the fire or later. The respiratory symptoms present before, during, and after the fire are summarized in Table 2. The neurological findings are described in another paper (Le Quesne et al., 1976).

\section{Gastrointestinal symptoms}

Altogether 11 men experienced nausea during the fire, two vomiting, and one abdominal discomfort in addition to nausea. Four other men, who had no gastrointestinal symptoms at the time of the fire developed symptoms the following day, three of them complaining of abdominal pain with diarrhoea and one experiencing nausea and vomiting. Gastrointestinal symptoms in all the men subsided within two days and there were no long-term ill effects.

\section{Respiratory symptoms}

These occurred at the time of the fire in some men while other men remained symptom-free until the next day (Table 3).

Immediate symptoms. Twenty-five men experienced irritation of the eyes, nose, and throat and 14 of them developed specific respiratory symptoms such as a tightness in the chest, breathlessness, and cough while at the scene of the fire. Two of the men coughed up frothy sputum but in the remainder the cough was unproductive. Immediate symptoms appeared more common among those who smoked (Table 4). Delayed symptoms. Seventeen men who had no respiratory symptoms during the fire developed respiratory symptoms the next day, after an interval of at least eight hours. A further 13 men complained of a new respiratory symptom after a similar delay, having experienced a different chest symptom at the time of the fire.

Other delayed symptoms were chest tightness, breathlessness, and cough with or without sputum. Eight men developed a productive cough while a further five said they felt as if they had a heavy cold.

Chest symptoms in those affected were at their worst during the first three days and thereafter gradually subsided. Those who produced sputum described it as white and frothy with a pungent taste causing a burning sensation in the mouth and throat.

Chest radiographs obtained during the week after the fire showed no lesion attributable to the exposure.

One week after the fire the peak flow rate (PFR, Wright peak flow meter) was measured in all symptomatic individuals and two weeks later the forced expiratory volume in one second $\left(\mathrm{FEV}_{1}\right)$ and forced vital capacity (FVC) were obtained with the patient seated.

\section{Follow-up observations}

After six months 31 men were seen again: fourteen 
TABLE 2

Respiratory Symptoms Present Before, During, and After the Fire

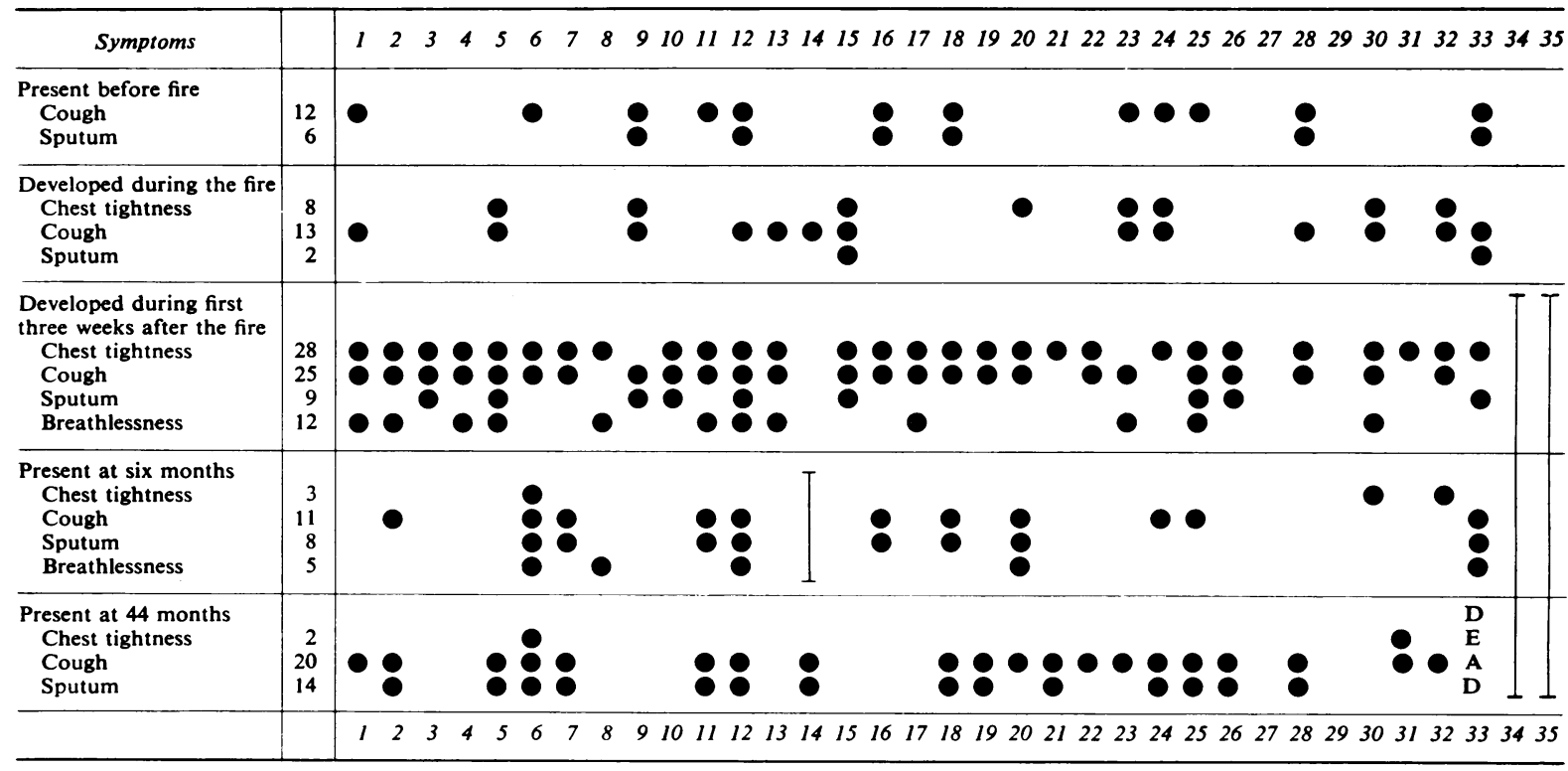

I Not seen

TA B LE 3

Respiratory Symptoms Related to Time of ONSET

\begin{tabular}{|c|c|c|c|c|}
\hline Time of onset & Cough & $\begin{array}{l}\text { Breathlessness } \\
\quad \text { and or } \\
\text { chest tightness }\end{array}$ & $\begin{array}{l}\text { Total no. } \\
\text { affected }\end{array}$ & ${ }^{\circ}{ }_{0}$ \\
\hline \multirow[t]{2}{*}{$\begin{array}{l}\text { Immediate } \\
\text { Delayed between eight hours and } \\
\text { three weeks }\end{array}$} & $\begin{array}{l}13 \\
15\end{array}$ & $\begin{array}{r}8 \\
22\end{array}$ & $\begin{array}{l}14 \\
30^{*}\end{array}$ & $\begin{array}{l}40 \\
86\end{array}$ \\
\hline & 28 & 30 & 31 & 88 \\
\hline
\end{tabular}

*Includes 13 who had a different symptom during the fire

TABLE 4

ResPiRatory Symptoms Related to SMOKING

\begin{tabular}{|c|c|c|c|c|c|}
\hline \multirow{2}{*}{ Firemen } & \multirow{2}{*}{ No. } & \multicolumn{2}{|c|}{ Cough } & \multicolumn{2}{|c|}{ Tightness and/or breathlessness } \\
\hline & & Immediate & Delayed & Immediate & Delayed \\
\hline $\begin{array}{l}\text { Smokers } \\
\text { Non- or ex-smokers }\end{array}$ & $\begin{array}{l}20 \\
15\end{array}$ & $\begin{array}{r}12^{*} \\
1^{*}\end{array}$ & $\begin{array}{l}8 \\
7\end{array}$ & $\begin{array}{l}6 \\
2\end{array}$ & $\begin{array}{r}13 \\
9\end{array}$ \\
\hline
\end{tabular}

*Significant difference between smokers and non- and ex-smokers

had persistent respiratory symptoms, mainly cough and/or chest tightness, and claimed an increased susceptibility to upper respiratory tract infections. Four men who had had symptoms of bronchitis before the fire felt that their symptoms had been aggravated and a further four men had developed a cough with regular sputum production for the first time. Of the four men with newly-developed 
symptoms three were in their third decade and three were non-smokers. Their symptoms appeared between three and six months after the fire and while all four had some respiratory symptoms in the days immediately after the fire only one had sputum production at that time.

Repeat measurements of the PFR, FEV 1 , and FVC at this time showed a very small decline in the mean FEV $_{1}$ and FVC which is not statistically significant (Table 5). The mean values of those in whom sputum production had appeared for the first time after the fire are compared in Table 6 with the remainder of the group. All indices except the FEV \% had fallen more in the group with the onset of sputum and these men accounted for almost all the small fall in the FEV 1 and the FVC, as shown in Table 5.

The next opportunity to study the group was in July 1971, that is 44 months after the fire, when 31 men completed the Medical Research Council(MRC) Questionnaire on Respiratory Symptoms (1966) and measurements of PFR, FEV 1 , and FVC were obtained. By this time 20 men had respiratory symptoms of some kind, either cough and/or sputum, breathlessness, or chest tightness. Of these, 12 were experiencing sputum production for at least three months of the year, six being classified as having simple bronchitis (an affirmative answer to questions 6 or 8 , and 10 in the MRC Questionnaire) and six as having chronic mucopurulent bronchitis (an affirmative answer to questions 6 or 8 , and 10 plus 12 or 21 in the MRC Questionnaire). Four of this group had suffered from a regular morning cough before the fire and two of these had also experienced regular morning sputum production. Their smoking habits had not changed significantly during the period; eight of the 12 had smoked cigarettes and one had been a pipe smoker at the time of the fire; their mean tobacco consumption had been equivalent to 14 cigarettes a day. At the end of the study period seven were still smoking cigarettes and one smoked a pipe with a mean tobacco consumption equivalent to 13 cigarettes per day. The mean tobacco consumption for the total group at the time of the fire had been equivalent to 14 cigarettes per day among 20 smokers, but there was no significant change in smoking habits during the study period.

Table 7 shows the mean values for PFR, FEV and FVC obtained at the end of the study period with the corresponding predicted normal values for the group (Cotes, 1975). The values obtained compare favourably with the predicted values, but when those with bronchitis are considered separately (Table 8) these values are well below the predicted values, except for the FVC in the group with chronic bronchitis. The numbers and the variability are such, however, that none of the apparent differences is statistically significant.

Of the total group studied only 28 men were seen on all three occasions. The loss per annum of FEV and FVC for the group during the $\mathbf{4 4}$ months is shown in Table 9. It would appear that for both the $\mathrm{FEV}_{1}$ and FVC the rate of loss during the first six

TABLE 5

Changes in Mean PFR (29 Subjects) and Mean FEV 1 , FVC, and FEV\% (31 Subjects) During the Six Months After the Fire

\begin{tabular}{l|c|c|c|c}
\hline \multicolumn{1}{c|}{ Date } & PFR $(l /$ min $)$ & $F E V_{1}(l)$ & $F V C(l)$ & $\frac{F E V \%}{F V C}$ \\
\hline December 1967 & 547 & 3.50 & 4.63 & 75.6 \\
June 1968 & 549 & 3.45 & 4.55 & 75.8 \\
\hline Change & +2 & -0.05 & -0.08 & +0.2 \\
\hline
\end{tabular}

TABLE 6

Changes in Mean FeV 1 and Mean fVC in Men With and Without the Onset of Sputum Six Months After the Fire

\begin{tabular}{l|cc||cc}
\hline \multirow{2}{*}{ Date } & \multicolumn{2}{|c|}{ With onset of sputum (4 cases) } & \multicolumn{2}{|c}{ Without onset of sputum (27 cases) } \\
\cline { 2 - 4 } & FEV $(l)$ & $F V C(l)$ & FEV $(l)$ & FVC $(l)$ \\
\hline December 1967 & 3.29 & 4.36 & 3.54 & 4.68 \\
June 1968 & 3.01 & 3.81 & 3.52 & 4.67 \\
\hline Change & -0.28 & -0.55 & -0.02 & -0.01 \\
\hline
\end{tabular}


TABLE 7

Mean Values for PFR, FEV 1 , AND FVC (31 SubJeCts) 44 Months After the Fire as CoMpared with Predicted Normal Values (Cotes, 1975)

\begin{tabular}{l|c|c|c}
\hline & $\begin{array}{c}P F R \\
(l / \text { min })\end{array}$ & $F E V_{1}(l)$ & $F V C(l)$ \\
\hline July 1971 & 532 & $3 \cdot 69$ & $4 \cdot 66$ \\
Predicted value & 575 & $3 \cdot 57$ & $4 \cdot 52$ \\
\hline Difference & -43 & $+0 \cdot 12$ & +0.14 \\
\hline
\end{tabular}

months was excessive, although not reliably so, as the change in $\mathrm{FEV}_{1}$ varied from a loss of 0.631 to a gain of 0.871 in individual men. Thereafter, however, there was little change and the overall picture was of a rate of loss of FEV 1 and FVC somewhat lower than would have been expected.

If the group is divided into three according to bronchitic symptoms (Table 10), the excessive rate of loss of FEV 1 during the first six months occurred mainly in those with symptoms of bronchitis and not in those without symptoms. After the first six months, however, subsequent losses in the symptomatic group were significantly less than in the asymptomatic group.

\section{Discussion}

Isocyanate compounds are now widely used in industry, mainly in the rubber, furniture, and paint industries. Toluene di-isocyanate (TDI) is the most widely used isocyanate compound in the United Kingdom but the use of diphenyl methane di-isocyanate (MDI) is increasing and naphthalene di-isocyanate (NDI) and hexamethylene di-isocyanate (HDI) are occasionally used. MDI and NDI are considerably less volatile than TDI and HDI, but in conditions in which volatilization could occur they can act as painful irritants to mucous membranes such as the conjunctiva, and to the respiratory tract
TABLE 9

Average Loss of FEV 1 and FVC Per AnNum During Whole Period in 28 Men of Mean Age 39.2 YeARS

\begin{tabular}{l|c|c}
\hline \multirow{2}{*}{ Period } & \multicolumn{2}{|c}{ Average loss per annum $(l)$} \\
\cline { 2 - 3 } & $F E V_{1}$ & \multicolumn{1}{|c}{$F V C$} \\
\hline First six months & $0.066 \pm 0.119$ & $0.216 \pm 0.153$ \\
Next 37 months & $0.014 \pm 0.019$ & (gain) $\begin{array}{r}-0.029 \pm 0.024 \\
\text { Whole period }\end{array}$ \\
$\begin{array}{l}\text { Expected loss } \\
\text { for normal men }\end{array}$ & $0.019 \pm 0.012$ & $0.010 \pm 0.020$ \\
(Cotes, 1975) & & 0.021 \\
\hline
\end{tabular}

as well as the skin. The effects of inhalation have been of concern and both acute and chronic changes in lung function in exposed workers have been reported (Fuchs and Valade, 1951; Zapp, 1957; Brugsch and Elkins, 1963; Gandevia, 1963; Munn, 1965; Williamson, 1965). A state of hypersensitivity resulting in an asthma-like syndrome has been the major industrial problem as it can occur with repeated exposure to small amounts of TDI. For this reason the threshold limit value formerly established at $0.1 \mathrm{ppm}$ has been lowered to $0.02 \mathrm{ppm}$, although there is evidence that even at levels below $0.02 \mathrm{ppm}$ acute changes in ventilatory capacity can occur (Peters et al., 1970).

Industrialists recognize the hazard and every precaution is taken to protect personnel at risk by making available detailed operating and medical codes of practice (British Rubber Manufacturers Association, 1971), but this paper describes how accidental massive exposure occurred in a group of firemen who were unaware of the hazard. There is little doubt that the firemen involved in fighting the factory fire described here were exposed to high concentrations of TDI intermittently during a period of eight hours and that acute symptoms occurred at the time of the fire and immediately after. Similar

TABLE 8

Mean Values for PFR, FEV 1 , and FVC in 12 Firemen with Bronchitis 44 Months After the Fire

\begin{tabular}{|c|c|c|c|c|c|c|}
\hline & \multicolumn{6}{|c|}{ Bronchitis } \\
\hline & \multicolumn{3}{|c|}{ Simple } & \multicolumn{3}{|c|}{ Chronic } \\
\hline & $P F R(l / \min )$ & $F E V_{1}(l)$ & $F V C(l)$ & $P F R(l / m i n)$ & $F E V_{1}(l)$ & $F V C(l)$ \\
\hline $\begin{array}{l}\text { July } 1971 \\
\text { Predicted value }\end{array}$ & $\begin{array}{l}492 \\
577\end{array}$ & $\begin{array}{l}3 \cdot 25 \\
3 \cdot 63\end{array}$ & $\begin{array}{l}4 \cdot 18 \\
4 \cdot 57\end{array}$ & $\begin{array}{l}490 \\
565\end{array}$ & $\begin{array}{l}3 \cdot 27 \\
3 \cdot 45\end{array}$ & $\begin{array}{l}4 \cdot 60 \\
4 \cdot 44\end{array}$ \\
\hline Difference & -85 & -0.38 & -0.39 & -75 & $-0 \cdot 18$ & +0.26 \\
\hline
\end{tabular}


TABLE 10

Average Loss of FEV 1 Per Annum in 11 Firemen With Bronchitis Compared with 17 Firemen Without BRONCHITIS

\begin{tabular}{l|c|c|c}
\hline \multirow{2}{*}{ Period } & \multicolumn{3}{|c}{ Bronchitis } \\
\cline { 2 - 4 } & None $(17$ men $)$ & Simple $(5$ men $)$ & Chronic (6 men) \\
\hline First six months & $0.038 \pm 0.158$ & $0.112 \pm 0.291$ & $0.103 \pm 0.266$ \\
Next 37 months & $0.021 \pm 0.026$ & -0.001 (gain) \pm 0.047 & $0.008 \pm 0.043$ \\
Whole period & $0.023 \pm 0.016$ & $0.010 \pm 0.030$ & $0.016 \pm 0.028$ \\
\hline
\end{tabular}

symptoms could occur in firemen dealing with any major fire, but this group of men had fought fires of equal and greater intensity without such striking and delayed symptoms. Many other chemicals were stored in the plant (Table 1) and it is conceivable that something other than TDI was responsible, but subsequent analysis of the firemen's movements plus the irrefutable evidence of a leakage of a large quantity of TDI, make it likely that TDI was responsible.

Having studied this group during a period of almost four years there is some evidence that the respiratory tract of 15 men $(43 \%)$ has suffered longterm damage. Of these, seven already had respiratory symptoms but they all felt that these had worsened since the fire. They considered that they were more susceptible to upper respiratory tract infections and had become intolerant of smoky environments such as cinemas and public houses. This had seriously interfered with the social life of some of the men. Only three of 12 men who had symptoms of bronchitis after 44 months had experienced cough and sputum before the fire. It is possible that their smoking habits might have contributed but there is little difference between the groups, as eight ( $66 \%$ ) of the bronchitics were smokers compared with 11 $(58 \%)$ of the remainder. It is also possible that such symptoms might have been complained of in an attempt to gain compensation but at the time of the last interview most of the claims for compensation had been settled. In most cases the general practitioners were able to confirm the men's statements concerning respiratory tract illnesses and knew of their apparent susceptibility to respiratory tract infections. As a group the firemen appeared to have a balanced attitude towards their symptoms and many seemed prepared to attribute at least some of their symptoms to increasing age and smoking habits.

The tests of ventilatory capacity obtained shortly after the fire compare favourably with the predicted normal values which is perhaps surprising after such a severe respiratory tract insult. No information about these indices before the fire is available but it may well be that in such a selected group of men, accustomed to a fairly high level of habitual activity, the results might be expected to be above the predicted values. The values obtained six months later showed a marked average decline although the change in $\mathrm{FEV}_{1}$ varied from a loss of 0.631 to a gain of 0.871 in individual men. But the excessive loss of FEV $_{1}$ occurred in those who had developed symptoms of bronchitis. This trend was subsequently reversed so that when finally examined almost four years later the values obtained were above the predicted normal values for the total group. Again those with symptoms of bronchitis had values below the predicted values. Possible changes in FEV 1 are schematically presented in Fig. 2 in which the mean value before the fire is estimated from the average normal rate of decline of FEV $_{1}$ of 0.031 a year.

It has been suggested that there is a clear correlation between loss of pulmonary function and exposure to fires (Peters et al., 1974). The rate of decline of ventilatory capacity in 1430 Boston firefighters studied during a two-year period was found to be more than twice the expected rate. However, the firemen described in this paper did not show a sustained reduction in ventilatory capacity but a marked decline during the six months after the fire with subsequent recovery.

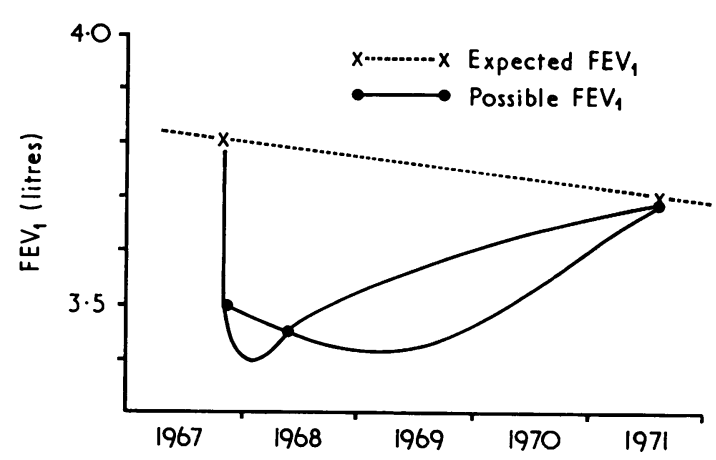

FIG. 2. Possible changes in $\mathrm{FEV}_{1}$. 
The evidence that permanent or long-term damage to the respiratory tract might have been caused by exposure to TDI is inconclusive, although there is a suggestion that this could be so.

We are grateful to the Somerset Fire Service for their co-operation throughout this study; to $\mathrm{Dr}$ J. C. Gilson and Dr P. D. Oldham for considerable help and advice, and to Carol Bevan who made the measurements of ventilatory capacity.

\section{References}

British Rubber Manufacturers Association (1971). Toluene di-isocyanate in industry-operating and medical codes of practice. A report of the Isocyanate Health Advisory Committee. BRMA Health Research Unit, Scala House, Birmingham.

Brugsch, H. G. and Elkins, H. B. (1963). Toluene diisocyanate (TDI) toxicity. New England Journal of Medicine, 268, 353-357.

Cotes, J. E. (1975). Lung Function Assessment and Application in Medicine, 3rd edition. Blackwell, Oxford.

Fuchs, S. and Valade, P. (1951). Étude clinique et experimentale sur quelques cas d'intoxication par le desmodur T (di-isocyanate de toluylene 1-2-4 et 1-2-6). Archives des maladies professionnalles, 12, 191-196.

Gandevia, B. (1963). Studies of ventilatory capacity and histamine response during exposure to isocyanate vapour in polyurethane foam manufacture. British Journal of Industrial Medicine, 20, 204-209.

Le Quesne, P. M., Axford, A. J., McKerrow, C. B., and Parry Jones, A. (1976). Neurological complications after a single severe exposure to toluene diisocyanate. British Journal of Industrial Medicine, 33, 72-78.

Munn, A. (1965). Hazards of isocyanates. Annals of Occupational Hygiene, 8, 163-169.

Peters, J. M., Murphy, R. L., Pagnotto, L. D., and Whittenberger, J. L. (1970). Respiratory impairment in workers exposed to 'safe' levels of toluene diisocyanate (TDI). Archives of Environmental Health, 20, 364-367.

-, Theriault, G. P., Fine, L. J., and Wegman, D. H. (1974). Chronic effect of fire fighting on pulmonary function. New England Journal of Medicine, 291, 1320-1322.

Williamson, K. S. (1965). Studies of di-isocyanate workers. 2. Transactions of the Association of Industrial Medical Officers, 15, 29-35.

Zapp, J. A., Jr. (1957). Hazards of isocyanates in polyurethane foam plastic production. Archives of Industrial Health, 15, 324.

Received for publication 15 January 1975

Accepted for publication 24 June 1975 